\title{
Avaliação qualitativa da técnica em Natação. Apreciação da consistência de resultados produzidos por avaliadores com experiência e formação similares.
}

\author{
S. M. Soares \\ R. J. Fernandes \\ C. M. Carmo \\ J. V. Santos Silva \\ J. P. Vilas-Boas
}

\author{
Faculdade de Ciências do Desporto e de Educação Física \\ Universidade do Porto \\ Portugal
}

https://doi.org/10.5628/rpcd.01.03.22

\section{RESUMO}

A avaliação qualitativa da técnica é um instrumento comunmente utilizado no dia a dia do treino da natação. Pelo facto de se apoiar apenas na observação simples dos movimentos dos nadadores, assume um carácter muitas vezes subjectivo, tendo já sido demonstrado que observações realizadas por avaliadores com formação e experiências diferentes produzem resultados distintos. O propósito deste trabalho foi estudar a heterogeneidade das avaliações realizadas por avaliadores diferentes, mas com experiências e formação semelhantes. Utilizámos uma amostra de 2 avaliadores e 20 nadadores da selecção regional pré-junior da Associação de Natação do Norte de Portugal, sendo 10 do sexo masculino e 10 do sexo feminino. O protocolo de avaliação consistiu na captação de imagens vídeo, recolhidas nos planos transverso e sagital a partir de duas janelas subaquáticas. Cada nadador realizou $2 \times 25$ metros em cada técnica (crol, costas, bruços e mariposa) à velocidade máxima. Cada avaliador observou as mesmas imagens, isoladamente, apontando os erros observados em listas de verificação previamente elaboradas. O tratamento estatístico dos dados consistiu no cálculo da percentagem total de erros realizados pelos nadadores em cada uma das quatro técnicas de nado e em diferentes fases e acções dentro de cada técnica. A comparação das proporções relativas para grupos independentes foi efectuada a partir de um teste $z$ (Microstat para computadores PC). O nível de significância foi estabelecido em $5 \%$. Apesar da similitude dos percursos académicos, graus de formação e experiências dos dois avaliadores, as observações efectuadas não foram coincidentes em todos os pontos da avaliação. Não se verificaram diferenças estatisticamente significativas entre as observações efectuadas pelos dois avaliadores, no que respeita ao número total de erros realizados pelos nadadores em cada técnica de nado, mas foram encontradas algumas diferenças com significado estatístico em diferentes fases e acções de cada uma das técnicas estudadas. Estes resultados sugerem que, mesmo com experiências e formação similares, avaliadores diferentes, escorados apenas em procedimentos qualitativos, tendem a obter resultados diferentes na apreciação de alguns gestos técnicos de nadadores.

Palavras chave: natação, técnica, avaliação qualitativa.

\author{
ABSTRACT \\ Qualitative Evaluation of Technique in Swimming: Analyses of \\ the Consistency of Results Produced by Evaluators with Similar
} Experiences and Theoretical Backgrounds.

The technical qualitative evaluation is an instrument frequently used on the day by day of swimming training. By the fact of using only the simple observation of the swimmers movements, it assumes a subjective profile. It has been already showed that observations performed by evaluators with different theoretical backgrounds and experiences produce different results. The main purpose of this work was to study the heterogeneity of evaluations performed by different evaluators with similar experiences and theoretical backgrounds. Two evaluators were studied over the performances of 20 swimmers, 10 boys and 10 girls, of the pre-junior regional team of the Swimming Association of North of Portugal. One video camera was used to assess swimmers move-ments, on the transverse and sagital plans, from underwater windows. Each swimmer performed a total of $2 \times 25$ meters on each swimming technique (crawl, backstroke, breaststroke and butterfly) using their maximal velocity. Both evaluators observed the same images independ-ently one of each other, pointing the identified errors in checklists previ-ously elaborated. The statistical treatment consisted both on the calcu-lation of the total percentage of errors performed by the swimmers in each one of the four swimming techniques and in different phases and actions inside each swimming technique. The comparison of the relative proportions for independent groups was performed using a $z$ test (Microstat for PC computers). The significance level was established in $5 \%$. Instead of the similarity of academic routs, academical degree and experiences of both evaluators, the observations made were not coincidents in all points of the evaluation. The comparison of the observations made by both evaluators on total number of errors performed by the swimmers in each swimming technique showed no significant results. Nevertheless, we have found some significant differences in some specific phases or actions in each one of the four studied tech-niques. This outcome suggests that different evaluators with the same background and experience tend to obtain different results on the evaluation of some movements within swimming techniques, when using qualitative procedures only.

Keywords: swimming, technique, qualitative evaluation. 


\section{INTRODUÇÃO}

A avaliação do desempenho técnico dos nadadores é uma tarefa diária dos treinadores de qualquer escalão competitivo. Esta avaliação, principalmente para os escalões mais jovens, é feita no dia a dia do treino, assumindo um carácter qualitativo e muitas vezes subjectivo: o treinador observa o movimento do nadador e corrige-o. Em períodos determinados e, principalmente, para os escalões competitivos mais evoluídos, as avaliações são suportadas por metodologias alternativas $(1,6)$, as quais apresentam menor índice de subjectividade, dada a utilização de um número superior de parâmetros quantitativos. A avaliação qualitativa da técnica de nado tem sido a metodologia mais utilizada em estágios organizados pela Federação Portuguesa de Natação e por diferentes Associações Regionais de Natação, nomeadamente no escalão pré-junior. O protocolo de avaliação consiste, geralmente, na realização de imagens vídeo, subaquáticas e de superfície, dos nadadores nadando cada uma das quatro técnicas de natação pura desportiva, respectivas partidas e viragens. Estas imagens são posteriormente analisadas por observadores experientes e são elaborados relatórios individuais do desempenho técnico de cada um dos nadadores e/ou relatórios contendo resultados por grupo (clube, associação, sexo, ...), salientando-se as principais incorrecções técnicas a tentar colmatar nos treinos subsequentes.

A questão que se nos coloca, neste momento, é a da possibilidade de, dada a subjectividade do método utilizado, avaliações realizadas por avaliadores diferentes, ainda que com experiências e formação semelhantes, produzirem resultados diferentes, ao ponto de comprometer este procedimento metodológico em estágios ou momentos de avaliação marcantes na época de treino.

\section{METODOLOGIA}

Para a realização deste estudo comparámos os resultados obtidos por 2 avaliadores sobre 20 nadadores pré-juniores, 10 do sexo masculino e 10 do sexo feminino, com idades compreendidas entre os $13 \mathrm{e}$ os 15 anos, pertencentes à selecção regional pré-junior da Associação de Natação do Norte de Portugal (ANNP).
Os dois avaliadores têm idades próximas (28 e 31 anos), a mesma formação de base (Licenciatura em Desporto e Educação Física, com especialização na área de desporto de rendimento - opção de Natação), os mesmos graus de pós-graduação (Grau de mestre em Ciências do Desporto), embora em áreas diferentes (Mestrado em Treino de Alto Rendimento e Mestrado em Desporto de Recreação e Lazer), são ambos docentes na mesma Faculdade e pertencentes ao mesmo gabinete. A sua actividade profissional difere na leccionação de anos distintos $\left(1^{\circ}\right.$ e $3^{\circ}$ ano da Licenciatura em Desporto e Educação Física) e no treino de equipas de clubes e nível competitivo diferentes: um é treinador de cadetes, com uma experiência de treino de 4 anos nesta categoria, e outro de infantis, também com 4 anos de experiência, aos quais acresce um ano de treino com a categoria de absolutos. Todos os nadadores treinados pelos avaliadores deste estudo estão filiados na ANNP. No âmbito do passado desportivo, ambos os sujeitos foram nadadores, um do Centro Desportivo Universitário do Porto, por um período de 3 épocas, entre os 13 e os 16 anos de idade, e outro do Futebol Clube do Porto, durante 7 épocas, entre os 8 e os 15 anos de idade.

O protocolo de avaliação decorreu durante um estágio pré-junior realizado pela ANNP, em cooperação com a Faculdade de Ciências do Desporto e de Educação Física da Universidade do Porto, e consistiu na recolha de imagens vídeo, realizadas nos planos transverso e sagital a partir de duas janelas subaquáticas localizadas, respectivamente, nas paredes testa e lateral da piscina. Foi pedido a cada nadador para realizar $2 \times 25$ metros de cada técnica (crol, costas, bruços e mariposa) à velocidade máxima. Cada avaliador realizou a sua observação isoladamente e com base nas mesmas listas de verificação (Fig. 1), uma para cada técnica de nado, as quais serviram como ficha de registo e guião, orientando a avaliação para pormenores específicos do desempenho técnico dos nadadores. As listas foram elaboradas tendo por base modelos técnicos descritos por Chollet (2), Costill et al. (3) e Maglischo (5). Os avaliadores participantes neste estudo têm uma experiência considerável na observação da técnica de nado. Inscrevem nos seus curricula a participação 


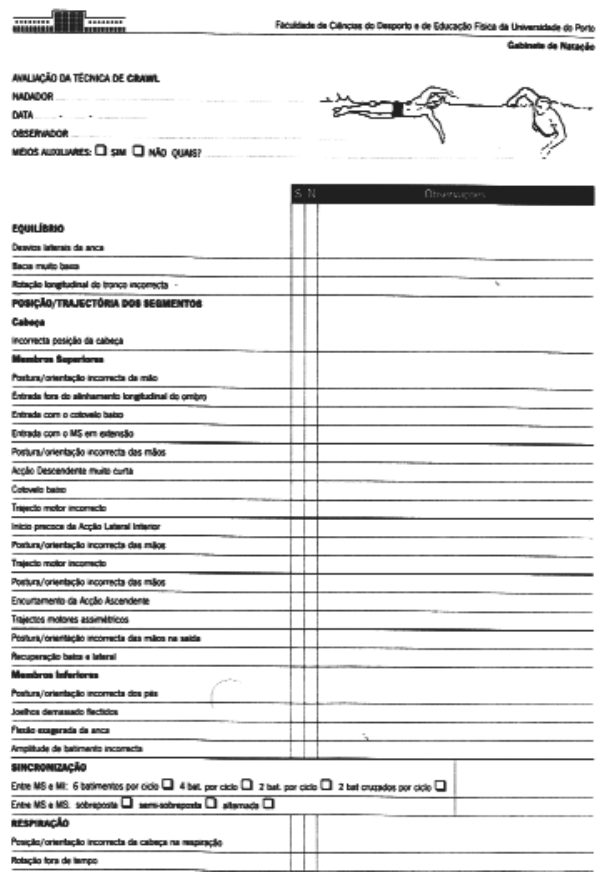

Figura 1 - Lista de verificação utilizada na técnica de crol.

em 9 protocolos de avaliação de nadadores pré-juniores (estágios organizados pela ANNP, pela ANVC e pela ANC). Em 7 das avaliações enunciadas foram utilizadas as mesmas listas de verificação do presente estudo. Nas restantes 3, foram utilizadas listas similares da Federação Portuguesa de Natação. $\mathrm{O}$ tratamento dos dados foi realizado em duas etapas:

(i) cálculo da percentagem total de erros (\%Te) realizados pelos nadadores em cada uma das quatro técnicas de nado, tendo-se utilizado a seguinte expressão (e1):

$\% \mathrm{Te}=(\mathrm{NTe} \times 100) \times(\mathrm{NTep} \times \mathrm{n})-1$

onde: NTe é o número total de erros realizados pelos nadadores observados, Ntep é o número total de erros possíveis na técnica avaliada e n é o número de nadadores observados. (ii) cálculo, pelo mesmo processo, da percentagem de erros referente a diferentes fases ou acções dentro de cada técnica, às quais chamamos categorias.

A comparação das proporções relativas para grupos independentes foi efectuada a partir de um teste $\mathrm{Z}$ (Microstat para computadores PC). O nível de significância foi estabelecido em $5 \%$.

\section{RESULTADOS}

Nas Figuras 2 e 3 pode observar-se uma comparação dos resultados obtidos por cada um dos avaliadores, referentes à totalidade de erros evidenciados, em cada uma das quatro técnicas de nado, pelos nadadores masculinos e femininos da ANNP.

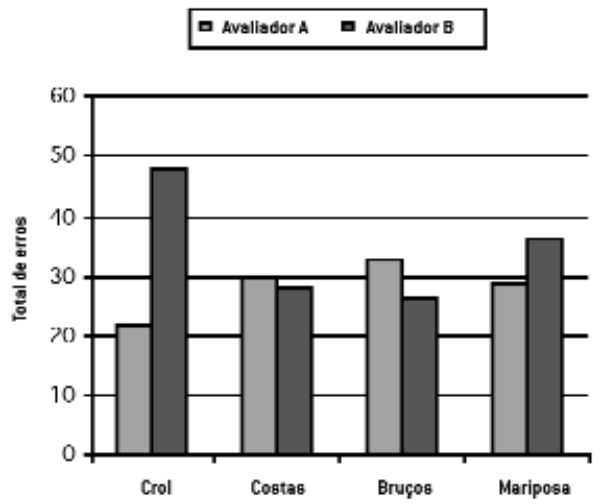

Figura 2 - Percentagem [\%] total de erros realizados pelo subgrupo masculino da ANNP, em cada uma das quatro técnicas de nado.

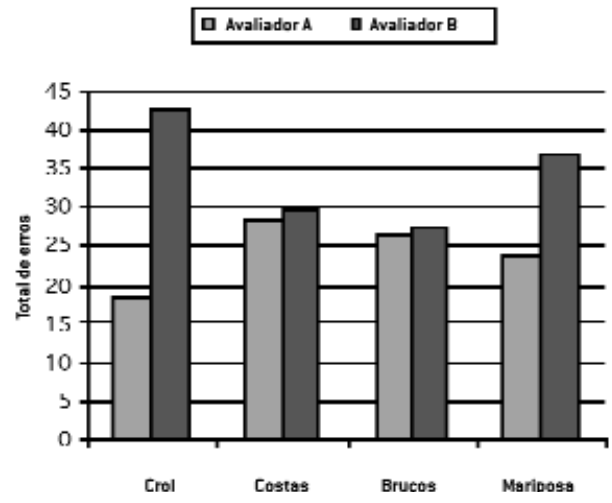

Figura 3 - Percentagem [\%] total de erros realizados pelo subgrupo feminino da ANNP, em cada uma das quatro técnicas de nado. 
Os resultados da avaliação mostram que os dois avaliadores têm resultados próximos nas técnicas de costas e bruços, semelhantes na técnica de mariposa, para o grupo masculino, e distintos na técnica de crol, em ambos os sexos, e na técnica de mariposa, no sexo feminino. Nenhuma das diferenças observadas foi estatisticamente significativa.

As Figuras 4 a 11 apresentam os resultados da avaliação de cada uma das técnicas analisadas pelos dois avaliadores.

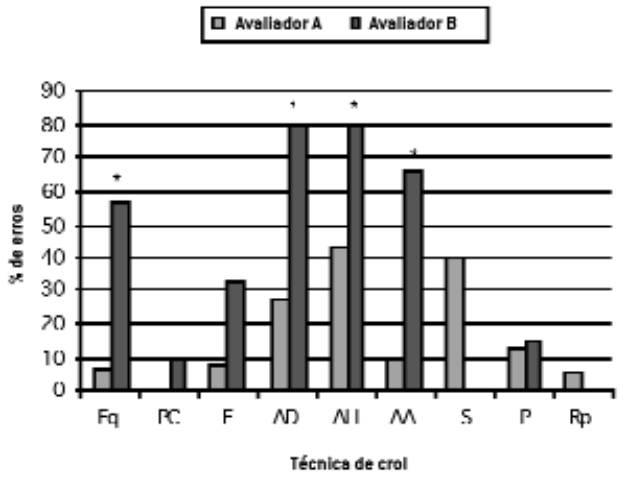

Figura 4 - Percentagem [\%] de erros realizados pelo subgrupo masculino da ANNP, em diferentes posições, acções e fases dos ciclos gestuais da técnica de crol.

Legenda: $\varepsilon q$ - equilíbrio; $P C$ - posição da cabeça; $\varepsilon$ - entrada; $A D$ - acção descendente; $A L I$ - acção lateral interior; $A A$ - acção ascendente; $S$ - saída; $P$ - pernada; Rp - respiração.

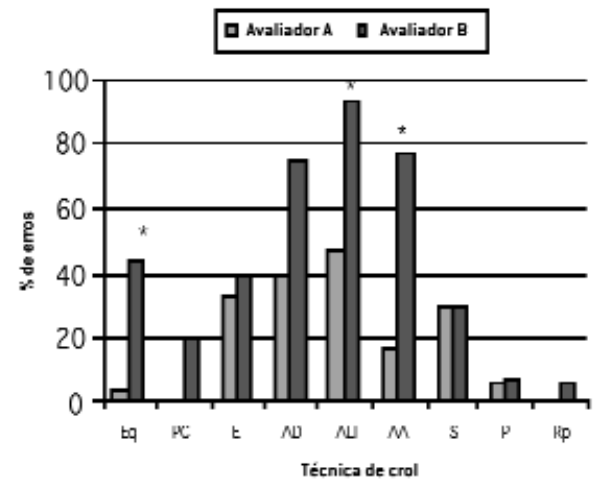

Figura 5 - Percentagem [\%] de erros realizados pelo subgrupo feminino da ANNP, em diferentes posições, acções e fases dos ciclos gestuais da técnica de crol.

Legenda: $\varepsilon q$ - equilíbrio; $P C$ - posição da cabeça; $\varepsilon$ - entrada; $A D$ - acção descendente; $A L I$ - acção lateral interior; $A A$ - acção ascendente; $S$-saída; $P$ - pernada; Rp - respiração.

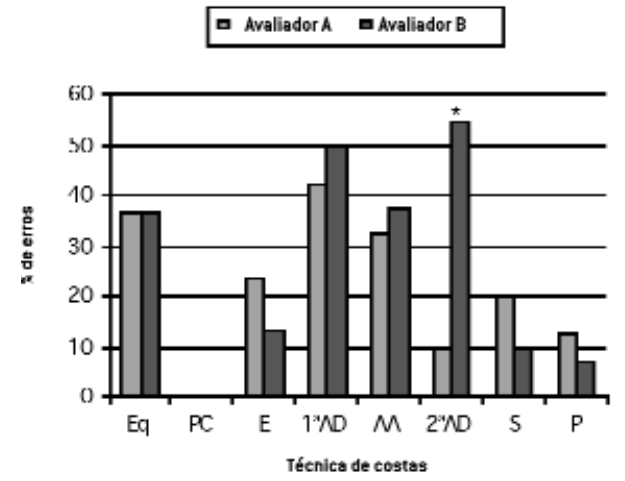

Figura 6 - Percentagem [\%] de erros realizados pelo subgrupo masculino da ANNP, em diferentes posições, acções e fases dos ciclos gestuais da técnica de costas.

Legenda: $\mathcal{E}$ - equilíbrio; $P C$ - posição da cabeça; $\mathcal{E}$ - entrada; $1^{a} A D$ - primeira acção descendente; $A A$ - acção ascendente; $2^{a} A D$ - segunda acção descendente; $S$ - saída; $P$ - pernada.

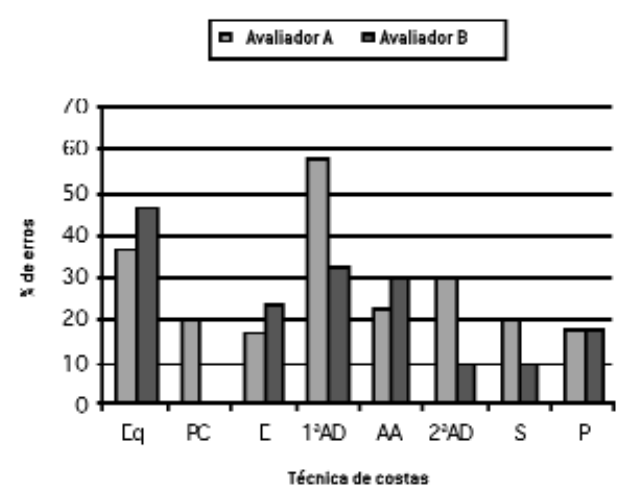

Figura 7 - Percentagem [\%] de erros realizados pelo subgrupo feminino da ANNP, em diferentes posições, acções e fases dos ciclos gestuais da técnica de costas.

Legenda: $\mathcal{E} q$ - equilíbrio; $P C$ - posição da cabeça; $\mathcal{E}$ - entrada; $1^{a} A D$ - primeira acção descendente; $A A$ - acção ascendente; $2^{a} A D$ - segunda acção descendente; $S$ - saída; $P$ - pernada. 


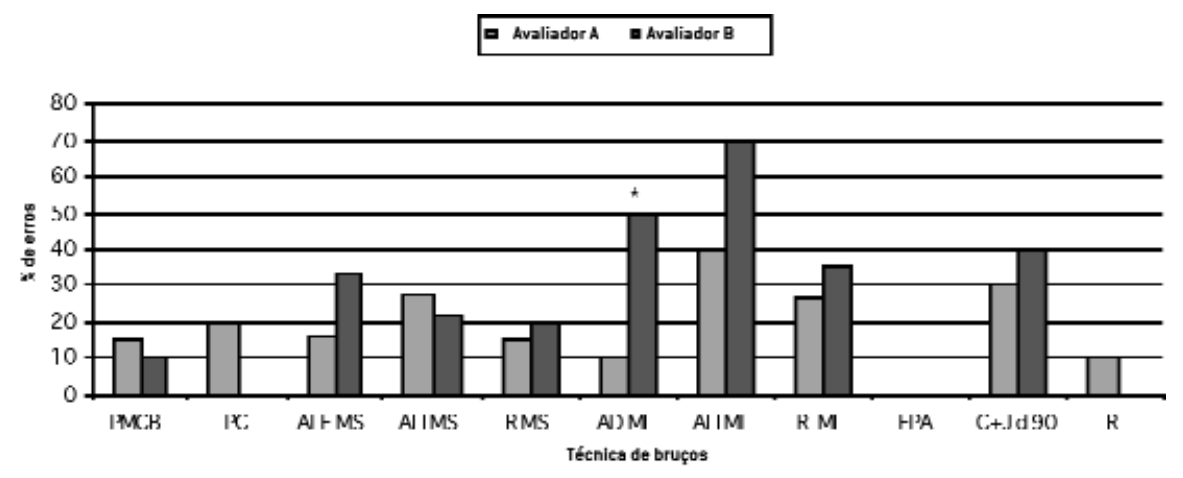

Figura 8 - Percentagem [\%] de erros realizados pelo subgrupo masculino da ANNP, em diferentes posições, acções e fases dos ciclos gestuais da técnica de bruços.

Legenda: PMCB - posição e movimento do corpo e bacia; PC - posição da cabeça; ALE MS - acção lateral exterior dos membros superiores; ALI MS - acção lateral interior dos membros superiores; $R$ MS - recuperação dos membros superiores; $A D \mathrm{MI}$ - acção descendente dos membros inferiores; $A L I \mathrm{MI}$ - acção lateral interior dos membros inferiores; $R \mathrm{MI}$ - recuperação dos membros inferiores; FPA - flexão precoce da anca; $C+J$ d 90 - posição de cotovelo e joelho com ângulo diferente de 90 graus; $R$ - respiração.

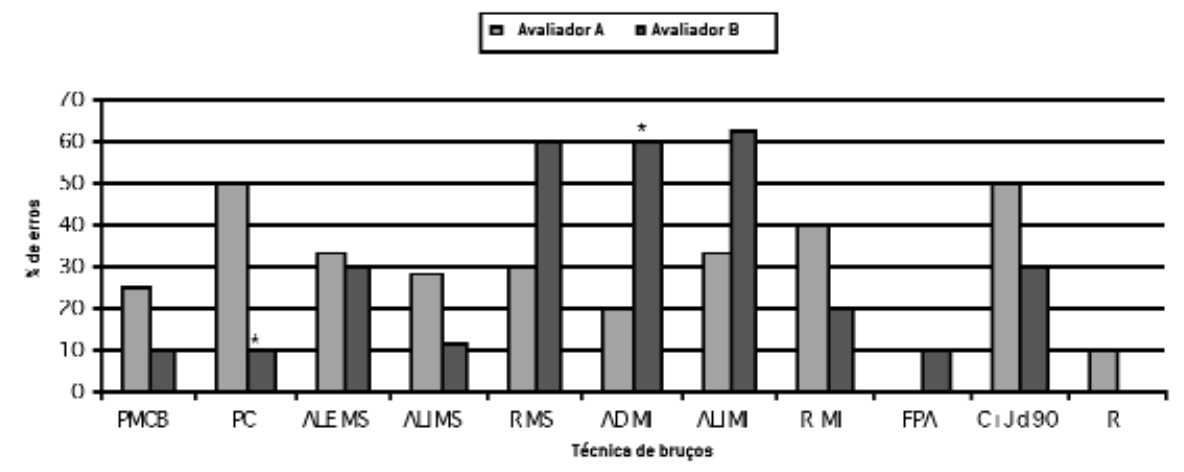

Figura 9 - Percentagem [\%] de erros realizados pelo subgrupo feminino da ANNP, em diferentes posições, acções e fases dos ciclos gestuais da técnica de bruços.

Legenda: PMCB - posição e movimento do corpo e bacia; PC - posição da cabeça; ALE MS - acção lateral exterior dos membros superiores; ALI MS - acção lateral interior dos membros superiores; R MS - recuperação dos membros superiores; $A D \mathrm{MI}$ - acção descendente dos membros inferiores; $A L I \mathrm{MI}$ - acção lateral interior dos membros inferiores; $R$ $\mathrm{Ml}$ - recuperação dos membros inferiores; FPA - flexão precoce da anca; $C+J$ d 90 - posição de cotovelo e joelho com ângulo diferente de 90 graus; $R$ - respiração. 


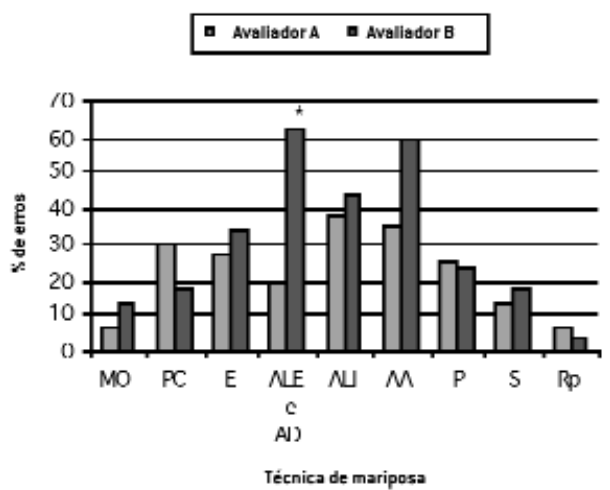

Figura 10 - Percentagem [\%] de erros realizados pelo subgrupo masculino da ANNP, em diferentes posições, acções e fases dos ciclos gestuais da técnica de mariposa.

Legenda: $M 0$ - movimento ondulatório; $P C$ - posição da cabeça; $\mathcal{E}$ - entrada $A L \varepsilon$ e $A D$ - acção lateral exterior e acção descendente; $A L I$ - acção lateral interior; $A A$ - acção ascendente; $P$ - pernada; $S$ - saída; $R p$ - respiração.

Nas Figuras anteriores pode observar-se que os resultados dos dois avaliadores parecem diferentes consoante a acção considerada em cada uma das quatro técnicas de nado, não se tendo, inclusivamente, observado um padrão consistente na incidência de erros registados pelos dois observadores.

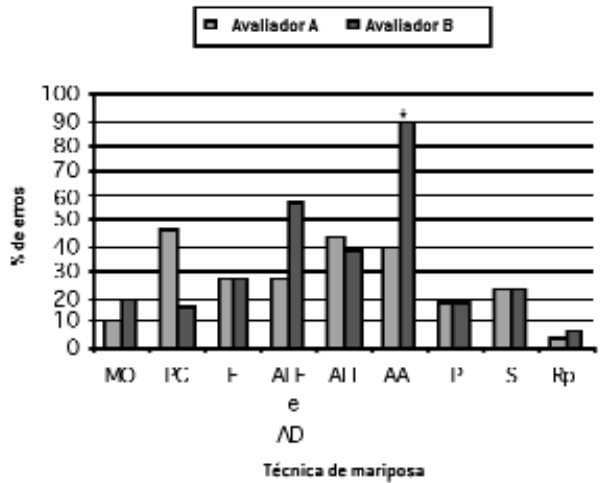

Figura 11 - Percentagem [\%] de erros realizados pelo subgrupo feminino da ANNP, em diferentes posições, acções e fases dos ciclos gestuais da técnica de mariposa.

Legenda: $M O$ - movimento ondulatório; $P C$ - posição da cabeça; $\mathcal{E}$ - entrada; $A L E$ e $A D$ - acção lateral exterior e acção descendente; $A L I$ - acção lateral interior; $A A$ - acção ascendente; $P$ - pernada; $S$ - saída; $R p$ - respiração.

Na Figura 12 encontram-se expressos graficamente os resultados referentes aos diferentes padrões de sincronização das técnicas de crol, costas e bruços. Também foi analisada a variante de nado de bruços utilizada por cada um dos nadadores da amostra.

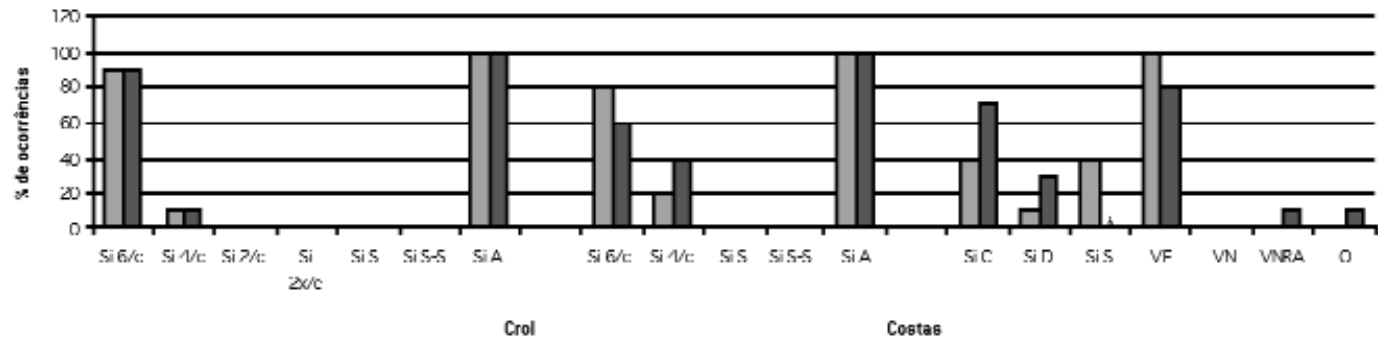

Figura 12 - Percentagem [\%] de ocorrências referentes aos padrões de sincronização das técnicas de crol, costas e bruços, e à variante de nado de bruços utilizada pelo subgrupo masculino da ANNP.

Legenda: Crol. Si 6/c - 6 pernadas por ciclo; Si 4/c - 4 pernadas por ciclo; Si 2/c - 2 pernadas por ciclo; Si $2 x / c-2$ pernadas cruzadas por ciclo; SiS - sincronização sobreposta; SiS-S - sincronização semi-sobreposta; SiA - sincronização alternada. Costas. Si 6/c - 6 pernadas por ciclo; Si 4/c - 4 pernadas por ciclo; SiS - sincronização sobreposta; SiS-S - sincronização semi-sobreposta; SiA - sincronização alternada. Bruços. SiC - sincronização contínua; SiD - sincronização descontínua; SiS - sincronização sobreposta; VF variante formal; VN - variante natural; VNRA - variante natural com recuperação aérea; 0 - outra. 


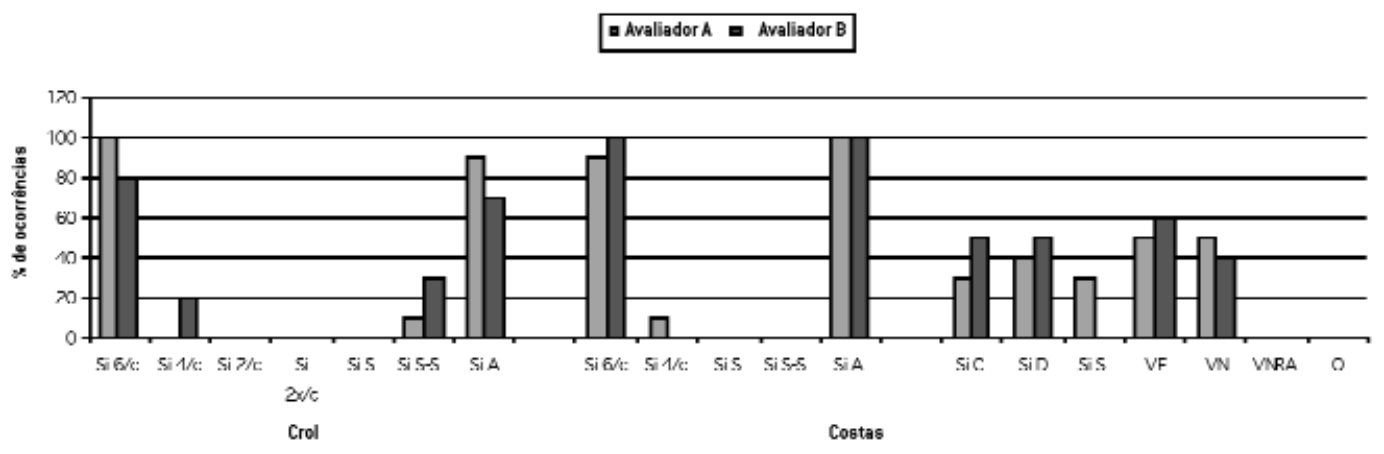

Figura 13 - Percentagem [\%] de ocorrências referentes aos padrões de sincronização das técnicas de crol, costas e bruços, e à variante de nado de bruços utilizada pelo subgrupo feminino da ANNP.

Legenda: Crol. Si 6/c - 6 pernadas por ciclo; Si 4/c - 4 pernadas por ciclo; Si 2/c - 2 pernadas por ciclo; Si 2 x/c - 2 pernadas cruzadas por ciclo; SiS - sincronização sobreposta; SiS-S - sincronização semi-sobreposta; SiA - sincronização alternada. Costas. Si 6/c - 6 pernadas por ciclo; Si 4/c - 4 pernadas por ciclo; SiS sincronização sobreposta; SiS-S - sincronização semi-sobreposta; SiA - sincronização alternada. Bruços. SiC - sincronização contínua; SiD - sincronização descontínua; SiS - sincronização sobreposta; VF - variante formal; VN - variante natural; VNRA - variante natural com recuperação aérea; 0 - outra.

Como pode observar-se nos vários gráficos apresentados, as avaliações realizadas pelos dois avaliadores são exactamente coincidentes apenas em alguns parâmetros. A maioria das observações evidenciou resultados com diferenças mais ou menos aproximadas e foram encontradas diferenças com significado estatístico em algumas categorias de desempenho técnico específicas.

\section{DISCUSSÃO DOS RESULTADOS}

Sanders (9) referiu, num estudo realizado no domínio da biomecânica da natação, que não é possível definir um estereótipo de nado perfeito. A técnica de nado mais correcta é aquela que traduz a melhor adequação mecânica do gesto técnico às características biofísicas de cada nadador em particular (9). A segunda afirmação é facilmente entendível se considerarmos que as características morfológicas e funcionais, bem como factores como o nível de condição física (4), por exemplo, determinam o desempenho técnico de cada nadador em particular. A primeira afirmação tem, na nossa opinião, de ser melhor explicitada, pelo facto de a proclamada inexistência de um modelo técnico ideal inviabilizar qualquer procedimento de avaliação qualitativa. A inexistência de um estereótipo de nado aplicável a todos os nadadores não significa inexistência de um modelo de referência, um modelo hipotético que consideramos ser muito próximo do modelo real de nado dos nadadores de elevado nível desportivo. Quando se realiza uma avaliação qualitativa, cada nadador, em função das suas características individuais, demonstra um nível de desempenho que estará mais ou menos próximo deste modelo teórico de nado. A melhor técnica de cada nadador será, à partida, aquela que mais se aproxima do padrão ideal, premissa que, todavia, carece de ratificação através de, por exemplo, uma avaliação comparada de níveis de economia motora. Será, provavelmente, pelo facto de subsistir uma possível inconsistência relativa no modelo de referência, bem como pela possibilidade de se interpretarem de forma diversa as subtilezas da particularização do modelo, nomeadamente em aspectos de maior detalhe, que é esperada alguma variabilidade nos resultados da observação dos dois avaliadores.

Entendendo e aceitando a variabilidade interindividual no desempenho técnico dos nadadores, ao realizar um estudo do tipo do que aqui apresentamos, poderíamos ser levados a concluir que as diferenças encontradas nos resultados obtidos pelos dois avaliadores seriam naturais e decorrentes, exactamente, do cunho pessoal que cada nadador coloca no nado de cada uma das técnicas e da interpretação que cada 
um faz do gesto técnico ideal, o que não sendo erro técnico, afasta o seu desempenho, mais ou menos, do modelo de nado de referência. Dizendo isto de forma mais simples, o entendimento do que é o melhor gesto para cada um dos nadadores pode ser diferente para cada avaliador, o que justificaria as diferenças nos resultados. No entanto, para que tal premissa pudesse ser tomada como verdadeira, seria necessário que cada avaliador conhecesse profundamente cada um dos nadadores avaliados, no sentido de ser capaz de distinguir uma adequação pessoal de um gesto técnico de um erro técnico, o que não aconteceu.

Aparentemente, o refinamento técnico com a idade e com a elevação do nível desportivo, traduzir-se-á numa progressivamente maior aproximação do gesto técnico do nadador ao modelo de referência, pelo menos nos seus aspectos mais macroscópicos. Nesta circunstância, portanto, justificar-se-á, progressivamente mais, o recurso a meios de avaliação quantitativa da técnica. Em contrapartida, os pré-juniores definem um escalão etário em que o desenvolvimento pubertário está a atingir o seu auge, estando as capacidades coordenativas largamente influenciadas pelos processos maturacionais (12). Esta é, como tal, uma fase em que pode ocorrer uma instabilidade técnica importante (12), instabilidade esta que não pode ser considerada exactamente como um "estilo" de nado personalizado, uma adaptação consistente e consolidada do modelo técnico às características particulares do sujeito, mas normalmente erros técnicos grosseiros não controlados. Além disso, a observação efectuada por cada um dos avaliadores teve como guião uma lista de verificação que aponta, exactamente, no sentido do apuramento de erros técnicos grosseiros, como uma posição corporal instável, um cotovelo pouco elevado ou uma pernada por finalizar.

Não podemos deixar de referir, também, dentro da mesma linha de pensamento, que os mesmos autores que referem a importância da adequação mecânica do gesto técnico às características biofísicas de cada nadador (9), são também autores de um vasto leque de trabalhos onde se estudam variações de desempenho de diferentes nadadores dentro da mesma técnica de nado $(7,8)$ e trabalhos onde se salientam erros técnicos importantes no desempe- nho dos nadadores nas diferentes técnicas de natação pura desportiva (10), os chamados erros grosseiros, típicos dos nadadores de escalões mais jovens, como os pré-juniores.

Face aos pressupostos antes enunciados, não seriam de esperar, de facto, as diferenças que se revelaram neste estudo, a não ser que sejam imputáveis à, apesar de tudo, diversa capacidade de observação e análise dos observadores.

A avaliação efectuada pelos dois avaliadores foi realizada com base naquilo que cada um considera como "nado tecnicamente correcto" e "erro técnico", ou seja, com base num modelo teórico decorrente das aprendizagens efectuadas durante a formação de cada um e experiências vividas na modalidade, quer como praticantes, quer como técnicos de natação. Dados os percursos similares dos dois avaliadores, seriam de esperar resultados mais homogéneos. No entanto, notam-se muitas diferenças, apesar das estatisticamente significativas serem, notoriamente, em menor número. Esta afirmação poderá ser entendida como uma sobrevalorização de apreciações impressionistas, em detrimento dos resultados estatísticos. Convirá, por isso, salientar que, no estudo de qualquer fenómeno, os resultados estatísticos têm de ser equacionados face à realidade que se está a observar. A estatística, muitas vezes, subvaloriza resultados muito importantes. No nosso caso, só se manifestaram estatisticamente significativas diferenças com um valor percentual superior a $40 \%$. Como tal, assumiríamos que para valores percentuais inferiores não haveria diferenças entre os dois avaliadores. Porém, na realidade, as diferenças com valor inferior a $40 \%$ têm que ser consideradas, uma vez que os resultados das avaliações são utilizados pelos treinadores e têm reflexo directo na intervenção sobre os nadadores.

Dentro das diferenças encontradas entre as observações dos dois avaliadores, seria, pelo menos, de esperar que as do subgrupo masculino fossem semelhantes ou, pelo menos, menos dissemelhantes, às do subgrupo feminino. Os nossos resultados mostram ausência de coerência para os resultados referentes aos dois sub-grupos de nadadores. Por exemplo, na técnica de mariposa, foram encontradas diferenças estatisticamente significativas na ALE e na AD para o grupo masculino e na AA para o grupo 
feminino. É estranho encontrar diferenças percentualmente diferentes para um mesmo aspecto técnico. Trata-se de olhar a mesma realidade, ou seja um nadador e uma nadadora a executar a mesma técnica, e realizar interpretações diferentes da mesma. Obviamente que, face aos resultados, desejaríamos conhecer o factor ou factores causais que justificam que dois avaliadores com características muito semelhantes tenham feito avaliações substancialmente diferentes em alguns dos parâmetros analisados. Contudo, o presente estudo permitiu-nos apenas realizar o diagnóstico das diferenças. Não conseguimos encontrar nenhum nexo de causalidade para os resultados. Como tal, atrevemo-nos apenas a dissertar um pouco sobre algumas das causas possivelmente explicativas do fenómeno observado.

Em primeiro lugar, não foi estudada a consistência intra-observador na utilização da lista de verificação, pelo que não sabemos se cada um dos avaliadores obteria os mesmos resultados observando os mesmos registos vídeo em momentos diferentes. No entanto, apesar de podermos encontrar alguma variabilidade intra-individual, a questão central continua a ser a da amplitude da diferença interindividual.

Analisando as características dos dois avaliadores, podemos verificar que, apesar da formação de base ser muito semelhante, os estudos de pós-graduação (mestrados) realizaram-se em áreas diferentes, uma ligada ao desporto de rendimento e outra ao de lazer, o que parece indiciar vocações de estudo e interesses diferentes e, como tal, possíveis perspectivações distintas da técnica de nado. No entanto, os percursos profissionais pós-mestrado parecem atenuar estas diferenças.

O envolvimento competitivo também é distinto. Um dos avaliadores está ligado a uma equipa de cadetes e outro a uma equipa de infantis, ambos com uma experiência de 4 anos. $O$ treinador de cadetes terá, à partida, uma sensibilidade técnica mais próxima das exigências do ensino, com preocupações eminentemente didácticas, e o treinador de infantis já se preocupará mais em adequar a técnica dos seus nadadores à imagem do nadador de alto nível. Aliás, este treinador tem um ano de experiência adicional no escalão de absolutos. Nos escalões mais jovens, as preocupações orientam-se para os erros mais gros- seiros e os treinadores poderão perder (ao nível da memória) alguma sensibilidade para aspectos mais finos do movimento, como sejam as posições das mãos nas várias fases dos trajectos subaquáticos, por exemplo, o que se poderá reflectir aquando do desempenho de papeis como avaliador técnico. O passado desportivo dos dois avaliadores é, também, substancialmente diferente. Existe uma diferença de 4 anos como nadadores e em clubes com protagonismo desportivo substancialmente diferente. Pensamos, no entanto, que a formação académica terá atenuado a influência, possivelmente diferente, das duas realidades de treino.

A leccionação $\left(1^{\circ}\right.$ e $3^{\circ}$ da licenciatura em Desporto e Educação Física) de anos distintos parece poder ser, também, uma explicação plausível para os resultados deste estudo, uma vez que, embora em ambos os anos os conteúdos curriculares apontem para um trabalho bastante específico da técnica de nado, um dos anos está mais vocacionado para a aprendizagem da técnica correcta $\left(1^{\circ}\right)$ e outro para a aprendizagem da forma de ensinar mesma técnica $\left(3^{\circ}\right)$, exigindo um trabalho muito mais específico no domínio da detecção e correcção de erros técnicos.

Outro factor a considerar será o da possível maior ligação afectiva ou outra para uma dada técnica ou técnicas de nado em particular, em desfavor de uma outra ou outras. As avaliações serão tão mais precisas quanto melhor o avaliador conhecer as técnicas e se identificar com elas. No entanto, os dois avaliadores do presente estudo são ambos especialistas em natação e conhecem profundamente cada uma das técnicas. Este argumento será tanto mais verdadeiro quanto menor for o grau de formação ou experiência do avaliador (11).

A acuidade visual colocada na observação, bem como a manutenção da mesma ao longo de todo o trabalho, é importante para a consistência dos resultados. Qualquer diferença num destes aspectos, entre os dois avaliadores, poderá diferenciar os resultados. Por fim, a técnica utilizada no preenchimento das listas de verificação também parece ser um factor passível de explicar algumas diferenças, uma vez que a experiência na sua utilização é igual para os dois avaliadores (participação em 7 protocolos de avaliação de nadadores). Existem, pelo menos, duas formas de realizar a avaliação: vendo o movimento do 
nadador na sua globalidade e memorizando-o ou vendo e analisando pequenas porções do movimento, o que exige uma menor capacidade de memorização. A primeira técnica poderá, eventualmente, ser associada a uma maior probabilidade de se perderem pequenos pormenores do movimento dos nadadores, comparativamente com a segunda, pelo que a utilização de técnicas de observação diferentes por parte dos dois avaliadores seria passível de induzir resultados diferentes. Saliente-se, contudo, que não realizámos qualquer controlo relativo ao método de observação utilizado por cada um dos nossos avaliadores, nem foram estabelecidos quaisquer critérios relativos ao preenchimento das listas de verificação, no sentido de minorar a subjectividade da observação. Face aos resultados aqui evidenciados, seria importante realizar estudos que comparassem mais avaliadores, com graus de formação e experiências semelhantes, controlando alguns factores externos passíveis de atribuir nexos de causalidade aos resultados.

\section{CONCLUSÕES}

Os resultados do presente estudo sugerem que observadores diferentes com características semelhantes, no que respeita a experiência desportiva, profissional e formação académica, apresentam resultados razoavelmente semelhantes quando realizam avaliações qualitativas da técnica de nado baseadas em registos vídeo e listas de verificação.

Porém, este estudo revelou algumas diferenças, entre ambos, com significado estatístico, o que nos leva a concluir que a avaliação qualitativa da técnica de nado, mesmo quando realizada por um especialista, carece de rectificação ulterior e deve ser apreciada com parcimónia.

\author{
CORRESPONDÊNCIA \\ Susana Maria Soares Ribeiro \\ Faculdade de Ciências do Desporto \\ e de Educação Física \\ Universidade do Porto \\ Rua Dr. Plácido Costa, 91 \\ 4200.450 Porto \\ Portugal \\ susana@fcdef.up.pt
}




\section{BIBLIOGRAFIA}

1. Cappaert, J. M. (1999). Biomechanics of swimming analysed by three-dimensional techniques. In: K. I. Keskinen, Komi, P. V. e Hollander, A. P. (eds), Biomechanics and Medicine in Swimming VIII. Jyvaskyla: University of Jyvaskyla, 141-145.

2. Chollet, D. (1997). Natation sportive. Approche scientifique. Paris: Éditions Vigot.

3. Costill, D.L.; Maglischo, E. W. e Richardson, A. B. (1992).

Swimming. Oxford: Blackwell Scientifique Publications.

4. Grosser e Neumaier (1986). Técnicas de entrenamiento.

Barcelona: Ediciones Martínez Roca S. A..

5. Maglischo, E. W. (1993). Swimming even faster. Moutain View, California: Mayfield Publishing Company.

6. Reischle, K. (1999). Objectives of and requirements for technique diagnosis in swimming. In: K. I. Keskinen, Komi, P. V. e Hollander, A. P. (eds), Biomechanics and Medicine in Swimming VIII. Jyvaskyla: University of Jyvaskyla, 147-152.

7. Sanders, R. (1996a). Some aspects of butterfly technique of New Zealand Pan Pacific squad swimmers. In: J. P. Troup; A. P. Hollander; D. Strasse; S. W. Trappe; J. M. Cappaert e T. A. Trappe (eds.), Biomechanics and Medicine in Swimming VII. London: E \& FN Spon, 23 - 28.

8. Sanders, R. (1996b). Breaststroke technique variations among New Zealand Pan Pacific squad swimmers. In: J. P. Troup; A. P. Hollander; D. Strasse; S. W. Trappe; J. M. Cappaert e T. A. Trappe (eds.), Biomechanics and Medicine in Swimming VII. London: E \& FN Spon, $64-69$.

9. Sanders, R. (2001a). Applying mechanical concepts to improve mid-pool swimming. XXIV Congresso Técnico-Científico da APTN (Edição em CD ROM). Rio Maior.

10. Sanders, R. (2001b). What we can learn and use from the latest swimming science research on starts and turns. XXIV Congresso Técnico-Científico da APTN (Edição em CD ROM). Rio Maior.

11. Sarmento, P. (1987). Observação de movimentos desportivos. Influência da formação e da experiência na identificação de erros técnicos em natação. Dissertação apresentada com vista à obtenção do grau de doutor em motricidade humana na especialidade de treino e organização desportiva. Lisboa: ISEF UTL.

12. Wilke, K. e Madsen, O.(1990). El entrenamiento del nadador juvenil. Buenos Aires: Editorial Stadium. 